\title{
Evaluation of impulse oscillation system: comparison with forced oscillation technique and body plethysmography
}

\author{
J. Hellinckx*,\#, M. Cauberghs ${ }^{\#}$, K. De Boeck*, M. Demedts ${ }^{\#}$
}

\begin{abstract}
Evaluation of impulse oscillation system: comparison with forced oscillation technique and body plethysmography. J. Hellinckx, M. Cauberghs, K. De Boeck, M. Demedts. (C) ERS Journals Ltd 2001.

ABSTRACT: The impulse oscillation system (IOS) has been developed recently to measure respiratory system resistance $(R \mathrm{rs})$ and reactance $\left(X_{\mathrm{rs}}\right)$ at different frequencies up to $\geqslant 25 \mathrm{~Hz}$. IOS has, however, not been validated against established techniques.

This study compared IOS with the classical pseudorandom noise forced oscillation technique (FOT) and body plethysmographic airway resistance $(R$ aw) in 49 subjects with a variety of lung disorders and a wide range of $R$ aw $\left(0.10-1.28 \mathrm{kPa} \cdot \mathrm{L}^{-1} \cdot \mathrm{s}\right)$.

Rrs,IOS was slightly greater than Rrs,FOT, especially at lower frequencies, with a mean \pm SD difference at $5-6 \mathrm{~Hz}$ of $0.14 \pm 0.09 \mathrm{kPa} \cdot \mathrm{L}^{-1} \cdot \mathrm{s}$. Comparisons with the wavetube technique applied on two analogues indicated an overestimation by IOS. Xrs,IOS

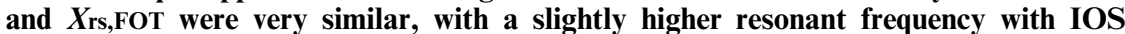
than with FOT (mean difference \pm SD $1.35 \pm 3.40 \mathrm{~Hz}$ ). Raw was only moderately correlated with Rrs-FOT and Rrs-IOS; although the mean differences were small $\left(0.04 \pm 0.14 \mathrm{kPa} \cdot \mathrm{L}^{-1} \cdot \mathrm{s}\right.$ for $R \mathrm{rs}_{6}, \mathrm{FOT}$ and $-0.10 \pm 0.14 \mathrm{kPa} \cdot \mathrm{L}^{-1} \cdot \mathrm{s}$ for $\left.R \mathrm{rs}_{5}, \mathrm{IOS}\right)$, IOS and FOT markedly underestimated high resistance values.

In conclusion, the impulse oscillation system yields respiratory system resistance and reactance values similar, but not identical to those provided by the forced oscillation technique.
\end{abstract}

Eur Respir J 2001; 18: 564-570.
*Dept of Paediatrics and ${ }^{\#}$ Laboratory of Pneumology, Katholieke Universiteit, Leuven, Belgium.

Correspondence: M. Demedts, Laboratory for Pneumology, U.Z. Gasthuisberg, Herestraat 49, B-3000 Leuven, Belgium.

Fax: 016346803

Keywords: Airway resistance body plethysmography forced oscillation technique impulse oscillation system impedance reactance

\section{Received: May 232000}

Accepted after revision April 262001

This study was funded by the National Fund for Scientific Research action "Care for Life", project numbers 7.0033.94, 7.0047.94 and 7.0078.94.
Recently, the Jaeger impulse oscillation system (IOS, Erich Jaeger, Hoechberg, Germany) has been introduced as a user-friendly commercial version of the forced oscillation technique (FOT). IOS offers data-analysis and an elaborate report, containing total respiratory system resistance $(R \mathrm{rs})$ and reactance $(X \mathrm{rs})$ at a wide range of frequencies. It also contains estimations of central and peripheral pulmonary mechanics based on a simple model. However, only limited data have been published on this technique and these reports were mainly related to results in asthmatic and healthy children [1-3].

The FOT was introduced by Dubors et al. [4] in 1956 as a method to characterize respiratory impedance and its two components, $R \mathrm{rs}$ and $X \mathrm{rs}$, over a wide range of frequencies. Briefly, flow oscillations generated by means of a loudspeaker are applied at the subject's mouth and superimposed on normal breathing. The resulting pressure signal, as well as the flow signal, are recorded and analysed. These signals are, in general, waveforms containing several frequencies. For each of these frequencies, the ratio of pressure to flow can be considered (i.e. the impedance), which is a complex number that contains information about both the ratio of the magnitude of pressure to flow and about the phase shift between these signals. Most often this complex number is represented by its real part, the respiratory resistance
$(R \mathrm{rs})$, and its imaginary part, the respiratory reactance $(X \mathrm{rs})$. Many studies have been published on FOT, especially since microprocessor techniques became available in the 1970 s, allowing the analysis of complex signals by Fourier transform [5-7]. The clinical potential of the method became apparent because it is rapid, demands only passive cooperation (i.e. no forced manoeuvres), and needs neither introduction of annoying devices (e.g. oesophageal balloon) nor frightening measuring conditions (e.g. closed body plethysmograph). It is especially appealing to children as it can be used routinely from 3 yrs of age onwards $[1,3,8]$. The FOT has also proved its usefulness in many pathological conditions $[9,10]$. In addition, the characteristics of the FOT have been widely studied $[11,12]$.

The IOS is, however, different from the classical FOT because an impulse (a rectangular wave form) rather than a pseudorandom noise signal (a mixture of several sinusoidal wave forms) is applied by the loudspeaker, and because of differences in data processing. No published data are available on accuracy of equipment and data handling, e.g. criteria for acceptance of data based on the coherence function [13,14] and on the applicability of implemented simple models simulating mechanics of the central and peripheral parts of the respiratory system $[10,15,16]$. 
The aim of the present study was, therefore, to compare the results obtained with IOS, FOT and body plethysmography over wide ranges of resistances in patients. Preliminary data have been published as an abstract [17]. In addition, the accuracies of IOS and FOT were evaluated on two mechanical structures by comparing the results with those obtained with the wave-tube technique [18], which can be considered as a reference technique for the measurement of acoustic impedance.

\section{Patients and methods}

Forty-nine subjects with widely different resistances were included in the study. Some were healthy, while others suffered from a variety of diseases including asthma, cystic fibrosis, chronic obstructive pulmonary disease and lung fibrosis. Ages ranged from 8-70 yrs (mean \pm SD: $24 \pm 19$ yrs).

At random, resistance was measured by the SensorMedics 6200 body plethysmograph (SensorMedics, Yorbe Linda, CA, USA; airway resistance (Raw)), the Jaeger impulse oscillation system (IOS, Erich Jaeger) $[1,2]$ and the Landsèr forced oscillation technique $[5,7,10]$ within a time period of $30-60 \mathrm{~min}$.
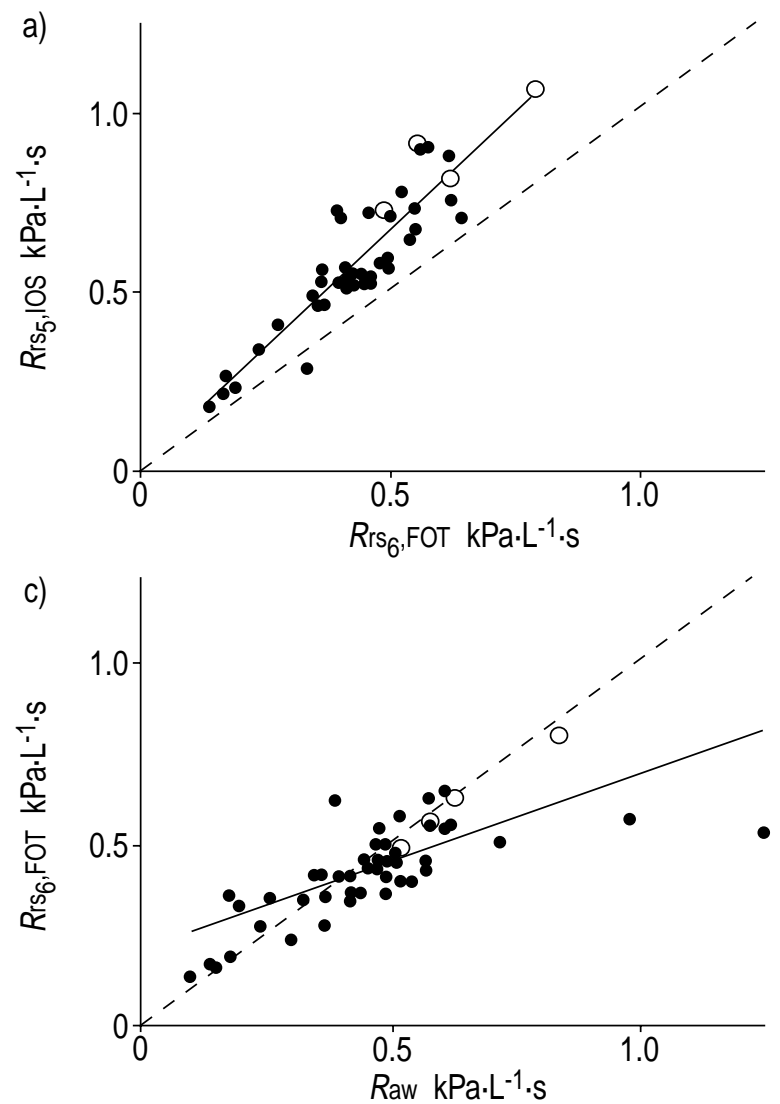

Raw was measured during rhythmic breathing at $0.5 \mathrm{~Hz}$ whilst keeping the cheeks supported in a constant-volume body plethysmograph, according to the technique of Dubors et al. [19], following the guidelines of the European Respiratory Society [6]. Raw was obtained as the pressure/flow slope between $\pm 0.5 \mathrm{~L} \cdot \mathrm{s}^{-1}$; the mean of three values was retained.

With the IOS, Raw and reactance ( $X$ aw) were calculated from the pressure/flow relationship obtained from impulses applied at the mouth during $\geqslant 32 \mathrm{~s}$ and were analysed from 2 to at least $25 \mathrm{~Hz}$ (yielding Raw and $X$ aw at 5, 10, 15, 20 and $25 \mathrm{~Hz}$, noted as $R \mathrm{rs}_{5}$,IOS, $X \mathrm{rs}_{5}$, IOS, etc.) and the resonant frequency (fo) $[1,2]$ (the latter being the frequency at which $X$ rs becomes zero, meaning that there is no phase shift between pressure and flow signals). The measurements were carried out according to the operating instructions provided by the manufacturer.

With the FOT, a pseudorandom noise signal was applied $[5,7]$ containing all the harmonics of $2-26 \mathrm{~Hz}$, and $R$ rs and $X$ rs were calculated as the mean value of three measurements of $16 \mathrm{~s}$ each. The signals were analysed up to $\geqslant 26 \mathrm{~Hz}$, resulting in $R$ rs and $X$ rs at fo, $6,8,10$, and so on up to $26 \mathrm{~Hz}$ (denoted $R \mathrm{Rr}_{6}$,FOT, $X \mathrm{rs}_{6}, \mathrm{FOT}$, etc. $)$.

Data analysis consisted of calculating mean $\pm \mathrm{SD}$,
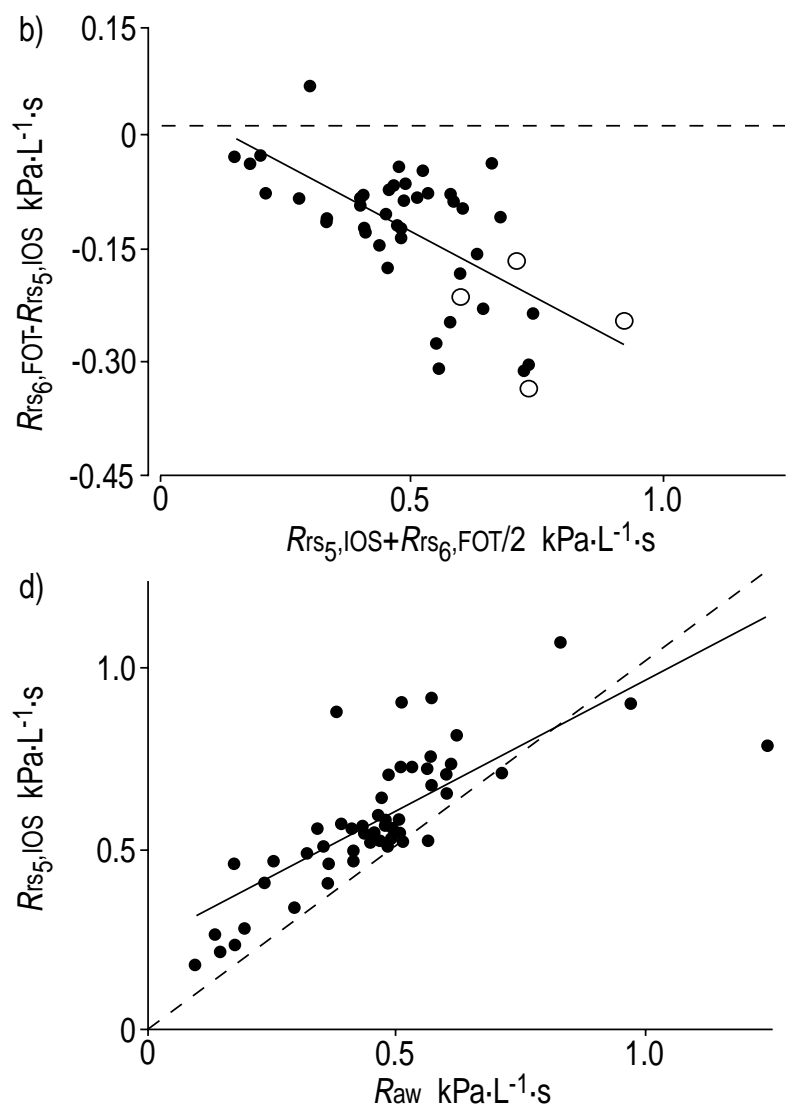

Fig. 1.-a) Relationship between resistance measured with the impulse oscillation system at $5 \mathrm{~Hz}\left(\mathrm{Rr}_{5}, \mathrm{IOS}\right)$ and resistance measured using the forced oscillation technique at $6 \mathrm{~Hz}\left(R_{\mathrm{rs}_{6}}, \mathrm{FOT}\right): R \mathrm{rs}_{5}, \mathrm{IOS}=\left(1.29 \times R_{\mathrm{rs}_{6}}, \mathrm{FOT}\right)+0.016 ; \mathrm{R}^{2}=0.83$, p $<0.001$. b) Bland-Altman plot of $R \mathrm{rs}_{5}, \mathrm{IOS}$ and $R \mathrm{rs}_{6}, \mathrm{FOT}$; SD of difference $=0.09 \mathrm{kPa} \cdot \mathrm{L}^{-1} \cdot \mathrm{s}$ and the slope was significantly different from 0 , p $<0.01$. c) Relationship between $R \mathrm{rs}_{6}, \mathrm{FOT}$

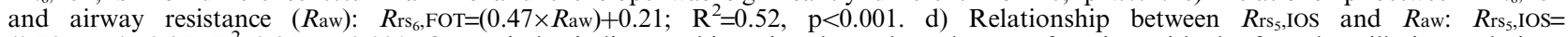
$(0.70 \times R$ aw $)+0.25 ; \mathrm{R}^{2}=0.25, \mathrm{p}<0.001$. Open circles indicate subjects in whom the coherence function with the forced oscillation technique was $<0.95$. Lines of identity (- - -) are shown in a), c) and d); solid lines are regression lines. 
linear regressions and dispersions from the line of identity, according to the method of BLAND and Altman [20].

In addition, resistance and reactance of two mechanical structures were measured: one consisted of three layers of meshed wire fitted inside a short tube, and the other had an additional layer of sintered copper resulting in a much higher resistance. The impedances obtained with the FOT and IOS were compared with those obtained with the wave-tube technique [18]. The latter is similar to the FOT, but the pneumotachograph is replaced by a $2-\mathrm{m}$ long cylindrical tube.

\section{Results}

This heterogeneous group of subjects showed a wide range of resistances, which thus made a reliable comparison of the three techniques possible. The mean value of $R_{\mathrm{rs}_{5}}$, IOS was $0.57 \mathrm{kPa} \cdot \mathrm{L}^{-1} \cdot \mathrm{s}$ (range 0.18 1.06 ), of $R \mathrm{rs}_{6}$, FOT $0.43 \mathrm{kPa} \cdot \mathrm{L}^{-1} \cdot \mathrm{s}$ (range $0.14-0.80$ ) and of Raw $0.47 \mathrm{kPa} \cdot \mathrm{L}^{-1} \cdot \mathrm{s}$ (range $0.10-1.28$ ).

Figure 1 shows the individual data points for $R \mathrm{rs}_{5}, \mathrm{IOS}, R \mathrm{rs}_{6}$,FOT and $R$ aw, with the regressions and correlation coefficients. $R \mathrm{rs}_{5}, \mathrm{IOS}$ and $R \mathrm{rs}_{6}$, FOT were closely correlated $\left(\mathrm{R}^{2}=0.83\right)$ with a difference (mean \pm
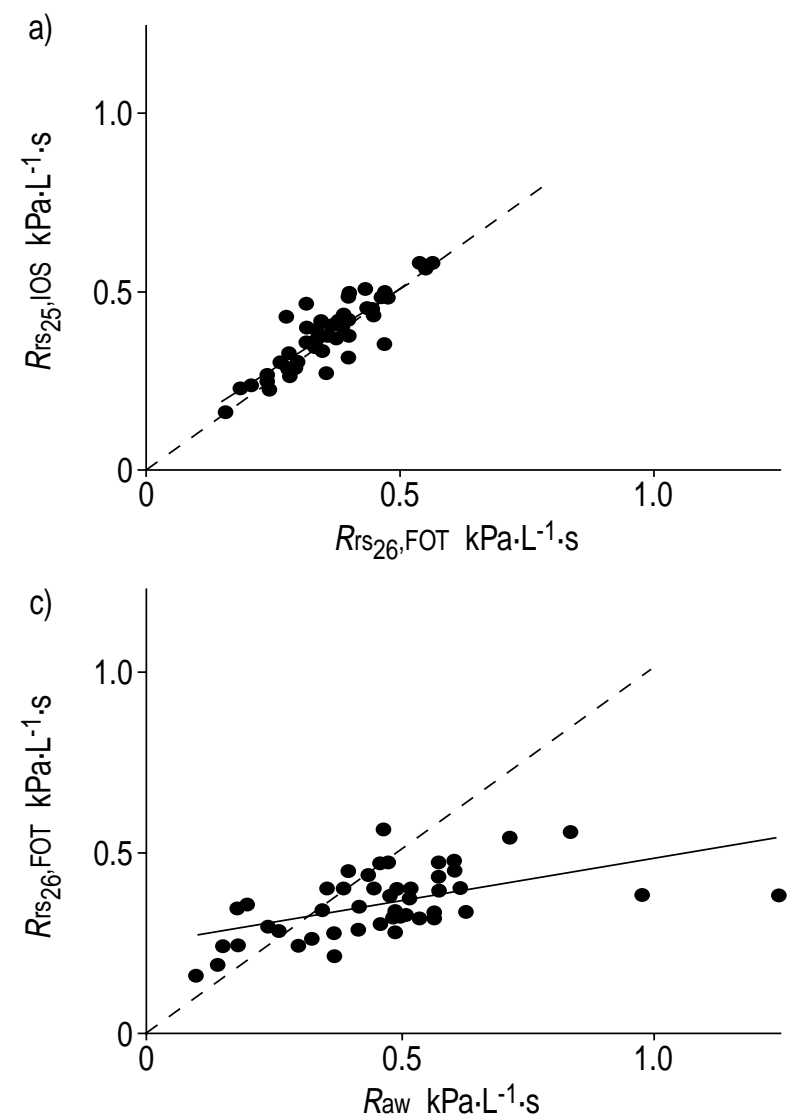

SD) of $0.14 \pm 0.09 \mathrm{kPa} \cdot \mathrm{L}^{-1} \cdot \mathrm{s}$, but the slope was different from 0 (fig. $1 \mathrm{~b}$ ). Except in one patient, where $R \mathrm{rs}_{5}, \mathrm{IOS}$ was higher than $R \mathrm{rs}_{6}$, FOT; a difference that increased at higher resistance values. Raw was also correlated with $R \mathrm{rs}_{5}, \mathrm{IOS}\left(\mathrm{R}^{2}=0.59\right)$ and with $R \mathrm{rs}_{6}$, FOT $\left(\mathrm{R}^{2}=0.52\right)$,

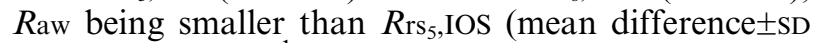
$-0.10 \pm 0.14 \mathrm{kPa} \cdot \mathrm{L}^{-1} \cdot \mathrm{s}$ ) and almost identical to $R \mathrm{rs}_{6}, \mathrm{FOT}$ (mean difference \pm SD $0.04 \pm 0.14 \mathrm{kPa} \cdot \mathrm{L}^{-1} \cdot \mathrm{s}$ ).

Figure 2 represents the data points and regression lines for $R \mathrm{rs}_{25}, \mathrm{IOS}, R \mathrm{rs}_{26}$, FOT and $R$ aw. Resistance values measured with IOS were slightly higher than those measured with FOT (mean difference \pm SD were $\left.0.03 \pm 0.05 \mathrm{kPa} \cdot \mathrm{L}^{-1} \cdot \mathrm{s}\right)$. These differences did not depend on the magnitude of resistance, i.e. the slope was not different from zero (fig. 2b). As frequency increased, the correlation between Raw and both FOT and IOS resistances became poorer $\left(\mathrm{R}^{2}\right.$ decreasing from 0.59 at $5 \mathrm{~Hz}$ to 0.28 at $26 \mathrm{~Hz}$ ) and both resistances were also markedly smaller than $R$ aw at high values.

Figure 3 depicts the data points and regressions for $X \mathrm{rs}_{5}$, IOS and $X \mathrm{rs}_{6}$,FOT on the one hand, and for f0,IOS and $\mathrm{f} 0, \mathrm{FOT}$ on the other hand. Both regressions were very close to the line of identity, although $X \mathrm{rs}_{6}, \mathrm{FOT}$ was somewhat higher than $X \mathrm{rs}_{5}, \mathrm{IOS}$ (mean difference \pm SD $0.07 \pm 0.07 \mathrm{kPa} \cdot \mathrm{L}^{-1} \cdot \mathrm{s}$ ) and $\mathrm{f} 0$,FOT was $1.35 \pm$ $3.40 \mathrm{~Hz}$ higher than $\mathrm{f} 0$,IOS.
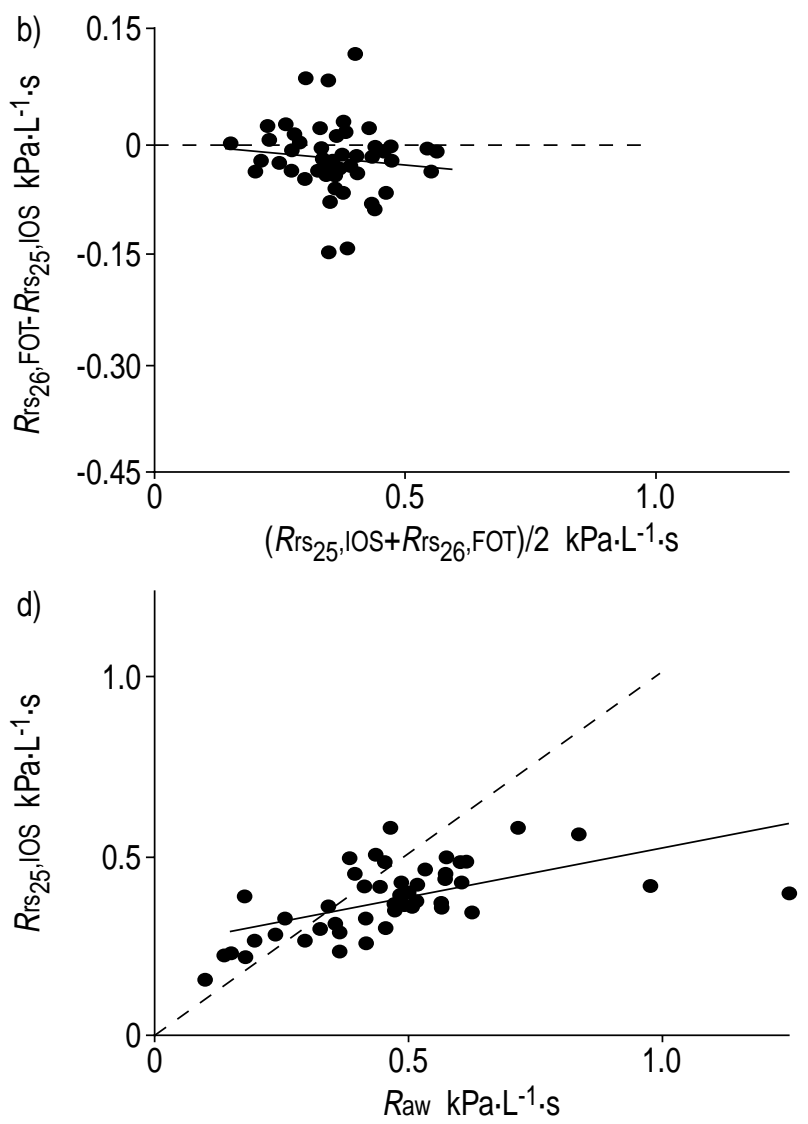

Fig. 2.-a) Relationship between resistance measured with the impulse oscillation system at $25 \mathrm{~Hz}\left(R \mathrm{rs}_{25}, \mathrm{IOS}\right)$ and resistance measured

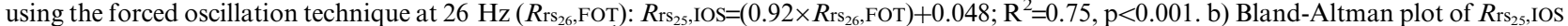
$R_{\mathrm{rs}_{25}}$,IOS and $R \mathrm{rs}_{26}$,FOT; SD of difference=0.05 $\mathrm{kPa} \cdot \mathrm{L}^{-1} \cdot \mathrm{s}$ but the slope was not significantly different from 0 . c) Relationship between $R \mathrm{rs}_{26}$, FOT and airway resistance $(R \mathrm{aw}): R \mathrm{rs}_{26}$, FOT $=(0.23 \times R$ aw $)+0.25 ; \mathrm{R}^{2}=0.28, \mathrm{p}<0.001$. d) Relationship between $R \mathrm{rs}_{25}$, IOS and $R$ aw: $R \mathrm{rs}_{25}$, IOS $=$ $(0.27 \times R$ aw $)+0.25 ; \mathrm{R}^{2}=0.33, \mathrm{p}<0.001$. Lines of identity (- - -) are shown in a), c) and d); solid lines are regression lines. 

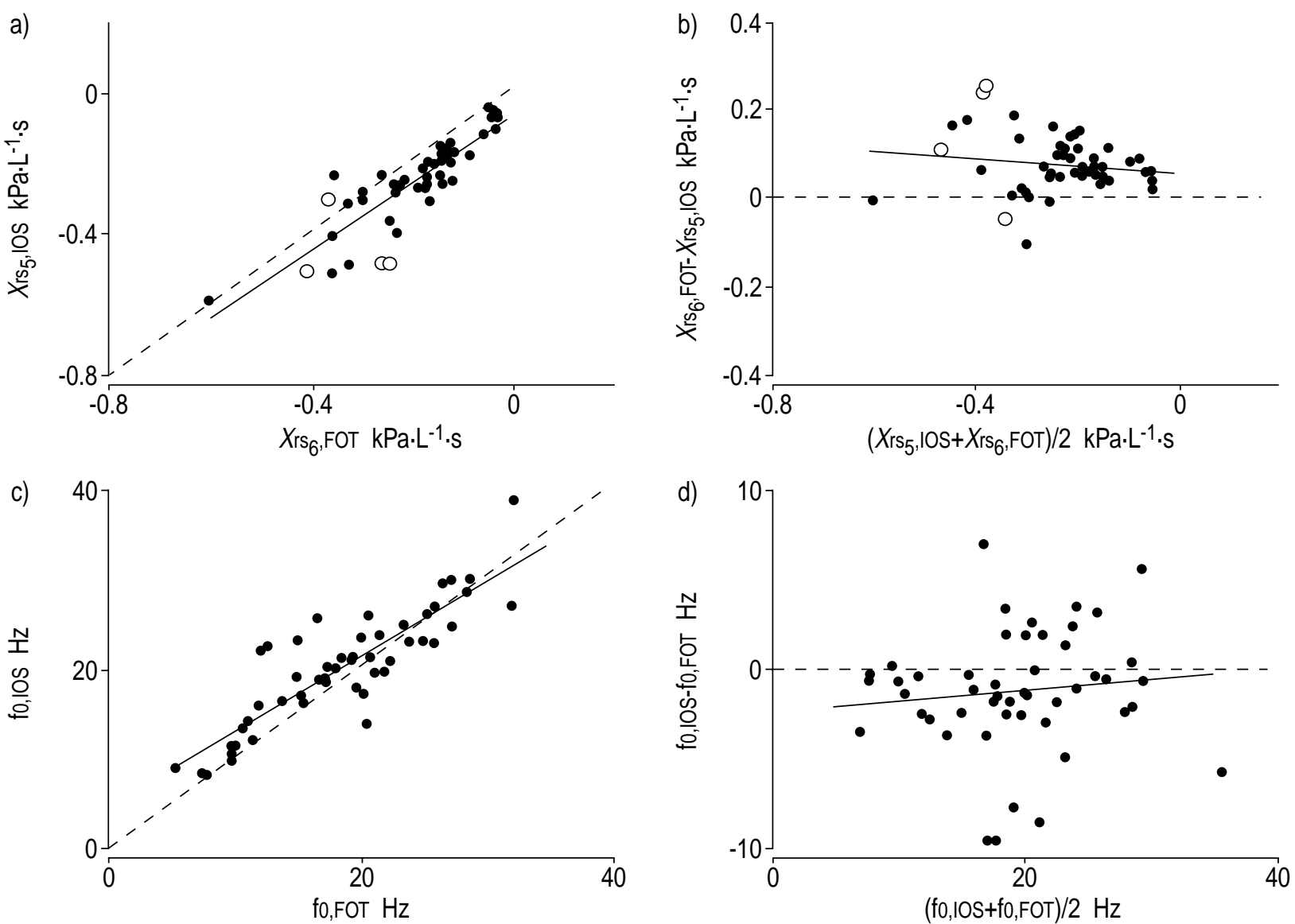

Fig. 3. -a) Relationship between reactance measured with the impulse oscillation system (IOS) at $5 \mathrm{~Hz}\left(X_{\left.\mathrm{rs}_{5}, \mathrm{IOS}\right)}\right.$ and reactance measured

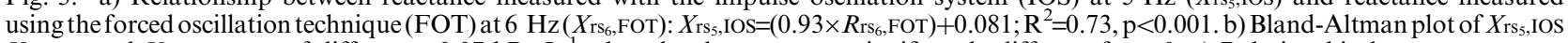
$X_{\mathrm{rs}_{5}, \mathrm{IOS}}$ and $X_{\mathrm{r}_{6}}, \mathrm{FOT}$; SD of difference $=0.07 \mathrm{kPa} \cdot \mathrm{L}^{-1} \cdot \mathrm{s}$ but the slope was not significantly different from 0 . c) Relationship between resonant frequency (fo) measured using IOS (fo,IOS) and FOT(f0,FOT): fo,IOS $=\left(0.82 \times f_{0}, \mathrm{FOT}\right)+4.68 ; \mathrm{R}^{2}=0.75, \mathrm{p}<0.001$. d) Bland-Altman plot of f0,IOS and fo,FOT; SD of difference=3.40 Hz but the slope was not significantly different from 0 . Lines of identity (- - -) are shown in a) and c); solid lines are regression lines.

Figure 4 shows the average resistance and reactance versus frequency curves for both FOT and IOS. At all frequencies, resistance with FOT was smaller than with IOS, with a difference that increased with decreasing frequency (inverse relationship). At all frequencies, reactance tended to be smaller with IOS.

Figure 5 shows that for the structures with both low ( $a$ and $c$ ) and high impedances ( $b$ and d), higher resistance values were clearly obtained with IOS than with either the FOT or the wave-tube technique at all frequencies.

Figure 6 shows that both FOT and IOS showed a decreasing amplitude of the pressure and flow signals for both structures as frequency increased. With the wave-tube technique it was found that both structures behaved linearly up to a pressure amplitude of about $0.15 \mathrm{kPa}$ (not shown). With the FOT, the overall pressure level was kept below $0.25 \mathrm{kPa}$ according to system recommendations [14]. With the IOS, pressure amplitudes of $0.59 \mathrm{kPa}$ occurred for the structure with the low impedance (a and c) and up to $1.10 \mathrm{kPa}$ for the structure with the high impedance (b and $d$ ). Thus the system recommendations were not fulfilled.

\section{Discussion}

These data show that, although there is a fairly good agreement between $R$ rs values measured with IOS and FOT at higher frequencies, the latter are smaller than those measured with IOS, especially at lower frequencies and for higher resistances. It is unlikely that a poor signal to noise ratio can account for this difference. Indeed, measuring high impedance values at lower frequencies is unfavourable for the signal-to-noise ratio (quantified by the coherence function). It has been verified for FOT, that a coherence function with a value of $<0.95$ indicates an unreliable result. Such verification, however, has not been performed for IOS. This means that the value of the coherence function that must be selected as a threshold for the reliability of the IOS results is not known, so no values were discarded.

Accordingly, all FOT data were also retained for further analysis, including those with a coherence value $<0.95$. Figures 1 and 3 illustrate that at $6 \mathrm{~Hz}$ this occurred in only four subjects (at higher frequencies no values $<0.95$ were observed) and that the 

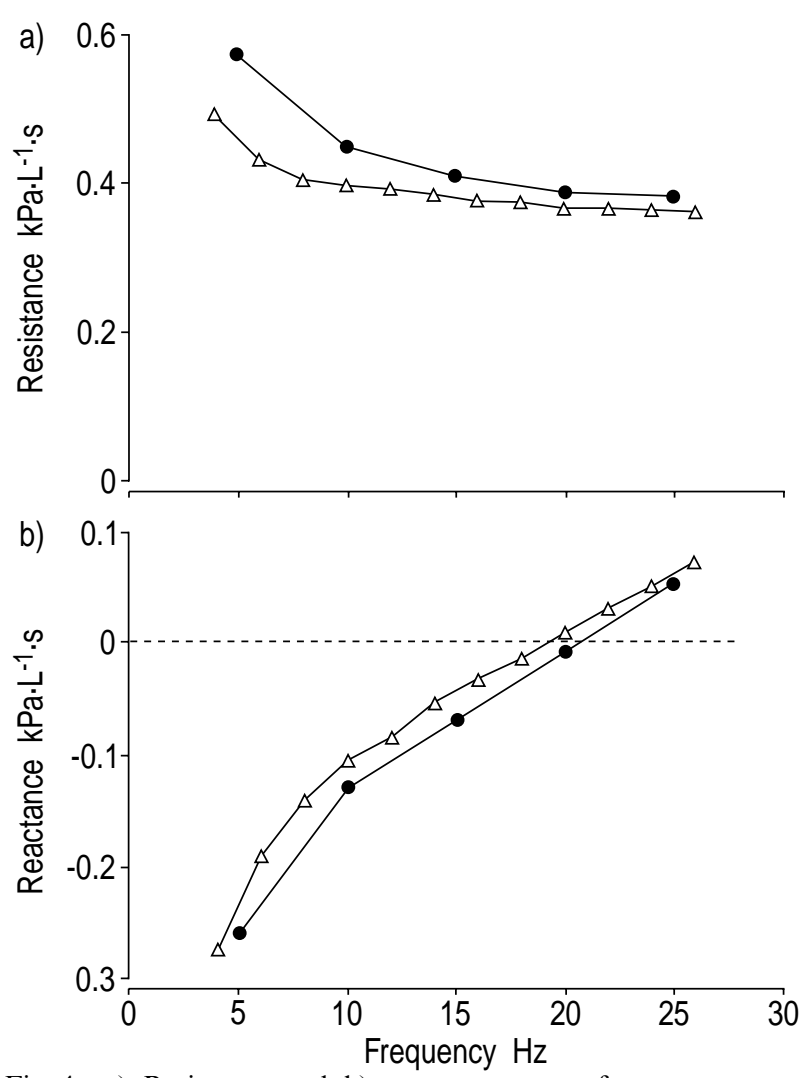

Fig. 4.-a) Resistance and b) reactance versus frequency curves $(\mathrm{n}=49)$. 0 : impulse oscillation system; $\triangle$ : forced oscillation technique. Airway resistance was $0.47 \mathrm{kPa} \cdot \mathrm{L}^{-1} \cdot \mathrm{s}$.
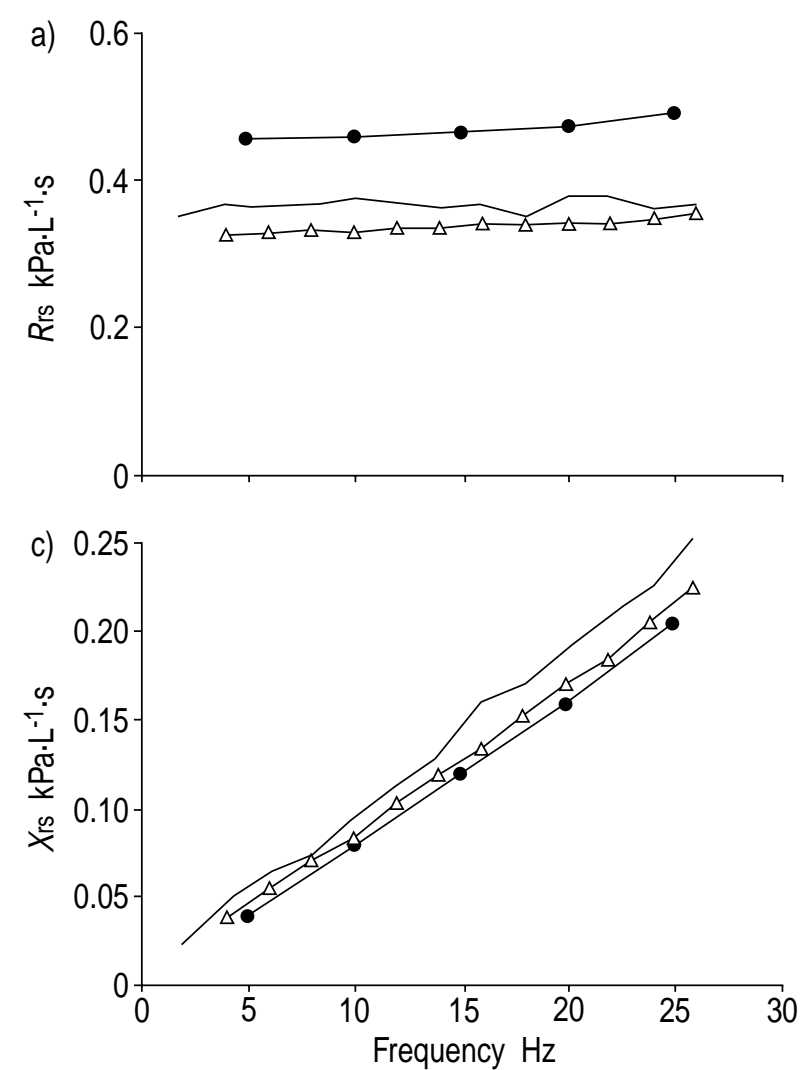

corresponding resistance and reactance values did not markedly influence the regression lines.

It might be tempting to attribute this increasing difference at the lowest frequencies and in the patients with the highest impedances to the fact that FOT is estimating resistance at $6 \mathrm{~Hz}$ and IOS at $5 \mathrm{~Hz}$ where higher resistance values can be expected due to the negative frequency dependence of resistance observed in those patients. However, this is unlikely to explain all the differences because $R$ rs,FOT at $4 \mathrm{~Hz}$ was also smaller than $R \mathrm{rs}_{5}$, IOS, although the former data were less reliable (18 out of 49 scored a coherence of $<0.95$ ).

It is more likely that this difference is due to an overestimation of the resistance by IOS. Indeed, the resistance and reactance of two mechanical structures (one with a low resistance and the other with a much higher resistance) were measured with FOT, IOS and the wave-tube technique [18]. The latter technique does not estimate mechanical impedance from the ratio of pressure to flow, but from the ratio of inlet to outlet pressure across the tube, and from the physics of the gas inside the tube. The ratio of two pressures can be measured more easily and accurately than the ratio of pressure to flow, so this technique can be considered as a reference technique for the measurement of acoustic impedances. The data in figure 5 clearly indicate higher resistance values measured with IOS, as compared with FOT and the wave-tube technique, at all frequencies, and for both the high and low impedance structures. This overestimation of resistance could be explained by the alinear behaviour of both structures when applying IOS. Indeed, from
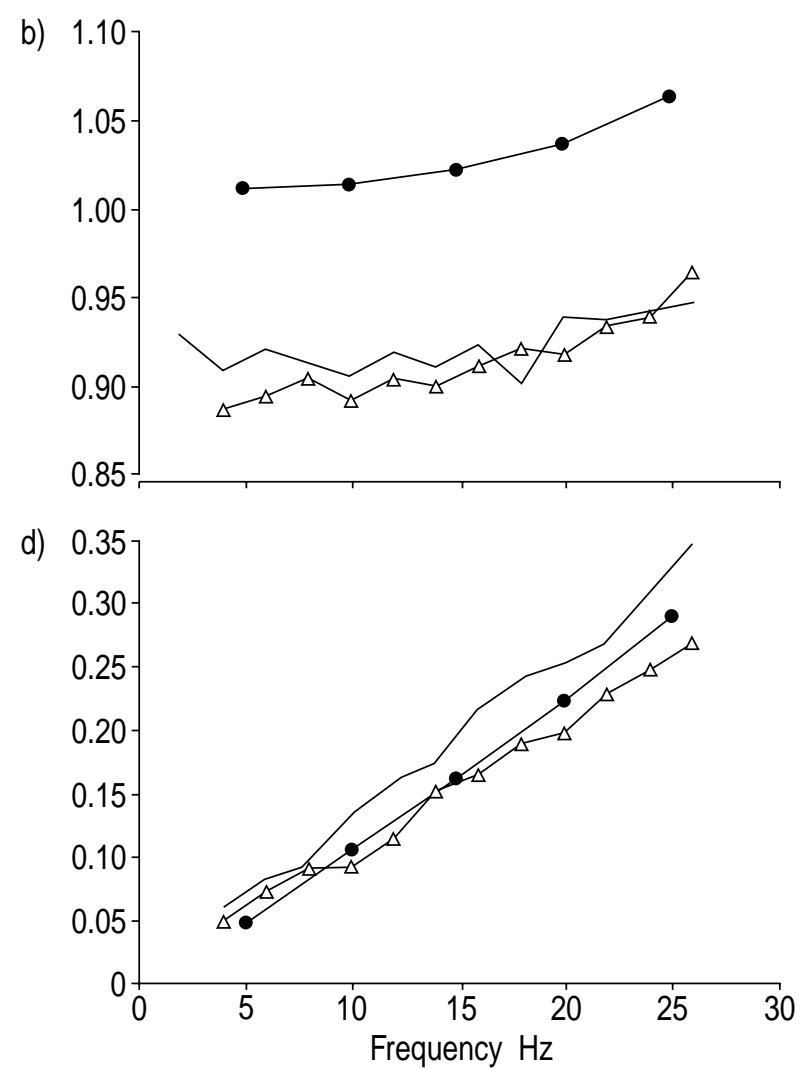

Fig. 5.-a) and c) resistance and b) and d) reactance versus frequency in two mechanical structures: a) and c) low impedance; b) and d) high impedance. $\bigcirc$ : impulse oscillation system, $\triangle$ : forced oscillation technique; solid lines: wave-tube technique. 


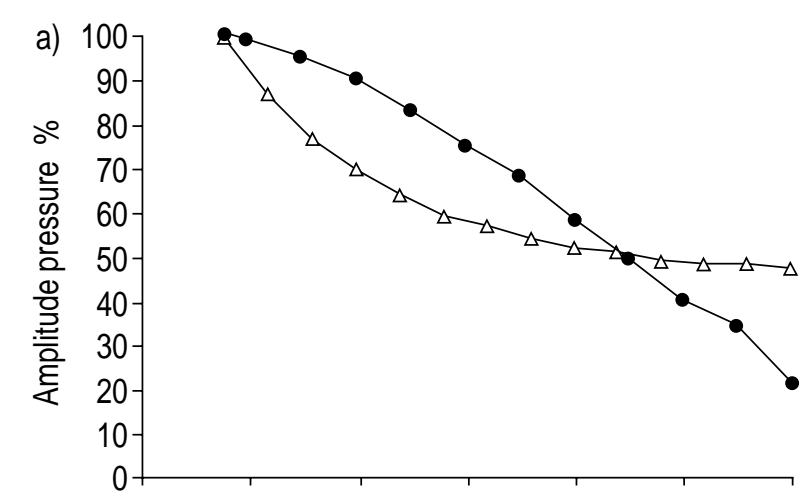

b)

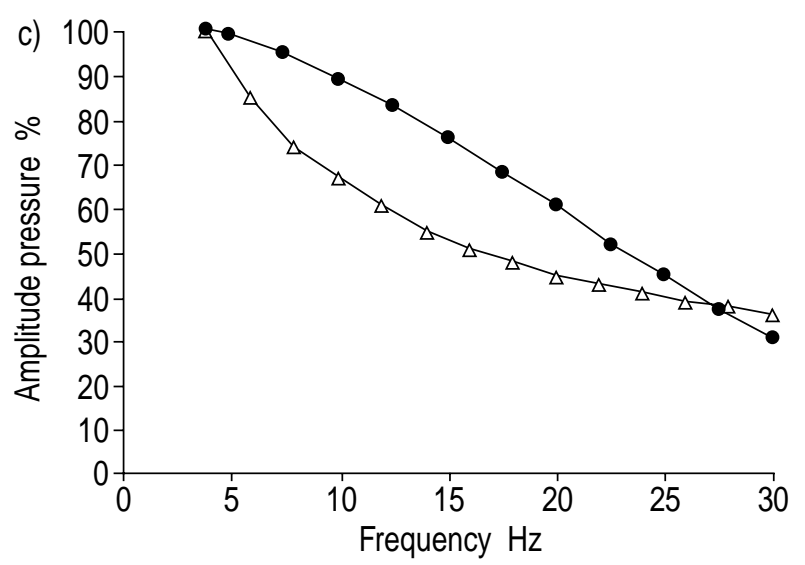

d)
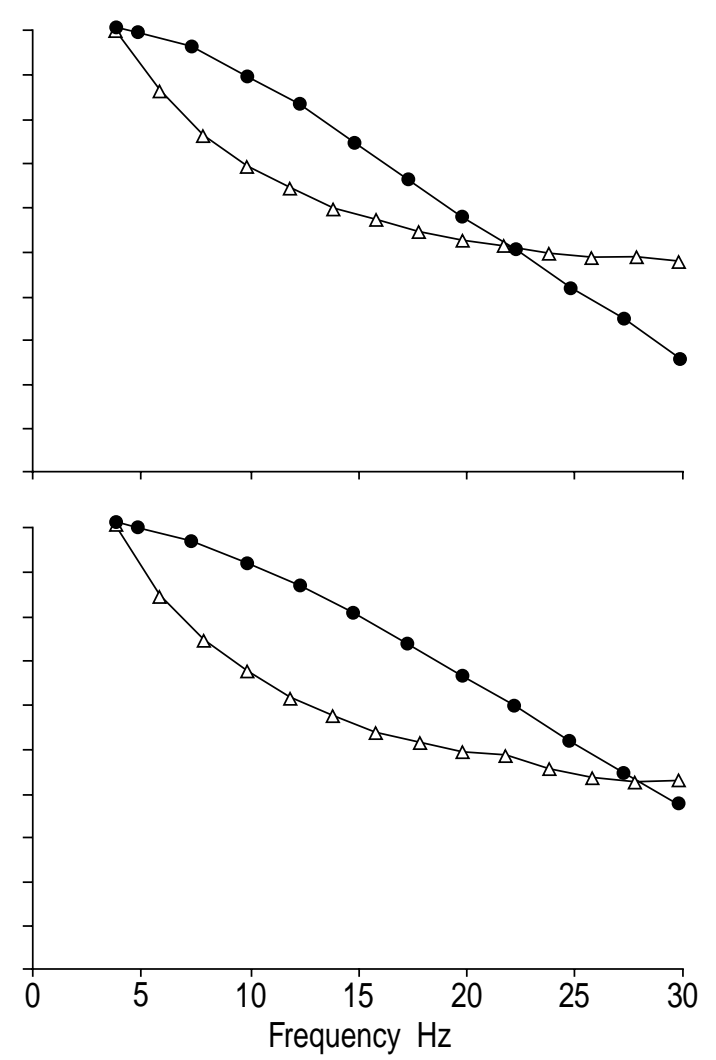

Fig. 6. - Amplitude-frequency curves of a) and b) pressure and c) and d) flow signals of the impulse oscillation system (IOS) and the forced oscillation technique (FOT). a) and c) illustrate results obtained with a small load (average resistance $0.34 \mathrm{kPa} \cdot \mathrm{L}^{-1} \cdot \mathrm{s}(\mathrm{absolute}$ values for IOS: pressure $0.59 \mathrm{kPa}$; flow $\left.1.69 \mathrm{~L} \cdot \mathrm{s}^{-1}\right)$ ); b) and d) represent results obtained with a larger load (average resistance $0.75 \mathrm{kPa} \cdot \mathrm{L}^{-1} \cdot \mathrm{s}$ (absolute values for IOS: pressure $1.10 \mathrm{kPa}$; flow $\left.1.40 \mathrm{~L} \cdot \mathrm{s}^{-1}\right)$ ). Values are expressed as a percentage of the amplitude at $4 \mathrm{~Hz}$. : IOS; $\triangle$ : FOT.

figure 6 it can be observed that, as frequency increases, both FOT and IOS show a decreasing amplitude of the pressure and flow signals. The shape of these amplitude/ frequency curves is somewhat different between both techniques; for the FOT the power at the lower frequencies is much more enhanced in order to compensate for the frequency content of the breathing signal. The overall pressure, however, is kept $<0.25 \mathrm{kPa}$, according to system recommendations [14], whereas for the IOS, pressure amplitudes of $0.59 \mathrm{kPa}$ were observed in measuring the structure with the low impedance, and up to $1.10 \mathrm{kPa}$ for the structure with the high impedance. This is far beyond the limits of linear behaviour of these structures, which were verified to behave linearly up to a pressure amplitude of about $0.15 \mathrm{kPa}$. This was performed with the wavetube technique, applying increasing power levels to the loud speaker, up to the level where measured impedance started to change, i.e. resistance increased.

The reactance values of IOS and FOT, as well as f0, were very similar to each other, except for $X_{\mathrm{rs}_{5}}$,IOS and $X_{\mathrm{rs}_{6}}$,FOT. From figure 4, however, it should be obvious that this difference can be explained by the difference in frequency, since reactance is strongly frequency dependent at this frequency. The fact that the reactances were more similar than the resistances with FOT and IOS is also an indirect indication that the differences in resistance could be due to nonlinearities.

The agreement between $R$ rs,IOS and Rrs,FOT estimates of $R$ aw is only moderately good. The correlation coefficients are rather poor $\left(\mathrm{R}^{2}=0.59-0.27\right)$ and the values are not superimposable. For resistance values in the normal range, $R$ rs with FOT is comparable with Raw, although somewhat larger. This has been attributed to the fact that the former technique measures total respiratory resistance, while body plethysmography measures only airway resistance [10]. Rrs with IOS is clearly larger than Raw, even for resistance values at $5 \mathrm{~Hz}$ exceeding the normal range. This might be another indication that IOS is overestimating respiratory resistance at lower frequencies. For higher resistance values, $R$ rs becomes progressively smaller than $R$ aw and this decrease was more pronounced at higher frequencies. This may be explained by the upper airway shunt (i.e. the loss of oscillatory flow into the cheeks) [16] and results in the frequency dependence of Rrs. This, therefore, makes these higher frequencies less accurate for clinical purposes. These resistances at higher frequencies are theoretically, however, not without importance. Indeed, the clinician should never be confined to one isolated frequency, but rather should consider the resistance/frequency curves and reactance/frequency 
curves as a whole. For clinical applications, the value at $5-6 \mathrm{~Hz}$ and the slope of the resistance/frequency curve may be most relevant.

The fact that the $R$ rs values obtained with IOS and FOT are related to each other, and behave similarly in comparison with body plethysmography, should not lead to the conclusion that they are interchangeable. Firstly, pseudorandom noise is applied in the FOT while an impulse is applied in the IOS. The former signal contains a limited number of frequencies while the latter does not have this limitation. This is in favour of the signal-to-noise ratio for the FOT. Indeed, keeping the magnitude of the overall signal within acceptable limits therefore reducing the number of frequencies, increases the power at each frequency. Secondly, the FOT recommendations have been formulated on the basis of apparatus characteristics, calibration, input signals and frequencies, data processing and criteria for data acceptance [14]. No such evaluations of IOS have been published.

Further investigations of the impulse oscillation system are warranted to confirm its reliability. In particular, measurements with standard calibrating systems should be considered [13, 14]. The present authors are aware that the different forced oscillation technique apparatus each have their own characteristics, and can yield some variation in results. However, it would be worthwhile to validate the impulse oscillation system apparatus against standard systems because this is built according to specific technical standards, which are different from those of the forced oscillation technique. Consequently, the impulse oscillation system may give different results for some pathophysiological events. Furthermore, normal values for the impulse oscillation system in different age categories [1,3] have to be established, and the degree and pattern of changes in different disease states (e.g. chronic obstructive pulmonary disease, upper airway obstruction, lung fibrosis etc.) have to be evaluated. Finally, although this issue was not addressed in the present study, the impulse oscillation system provides estimates of central and peripheral pulmonary mechanics based on a model of the respiratory system. These estimates have not been critically investigated and no evidence in the literature has been found to support their validity. Until this validity is established, these estimates should be viewed with suspicion.

\section{References}

1. Bisgaard H, Klug B. Lung function measurement in awake young children. Eur Respir J 1995; 8: $2067-$ 2075.

2. Klug B, Bisgaard H. Measurement of lung function in awake 2-4-years-old asthmatic children during methacholine challenge and acute asthma: a comparison of impulse oscillation technique, the interrupter technique and transcutaneous measurements versus whole body-plethysmography. Pediatr Pulmonol 1996; 21: 290-300.
3. Hellinckx J, De Boeck K, Bande-Knops J, van der Poel M, Demedts M. Bronchodilator response in 3-6.5 years old healthy and stable asthmatic children. Eur Respir J 1998; 12: 438-443.

4. Dubois $\mathrm{AB}$, Brody $\mathrm{AW}$, Lewis $\mathrm{DH}$, Burgess $\mathrm{BF}$. Oscillation mechanics of lungs and chest in man. J Appl Physiol 1956; 8: 587-594.

5. Landsèr FJ, Nagels J, Demedts M, Billiet L, Van de Woestijne KP. A new method to determine frequency characteristics of the respiratory system. $J$ Appl Physiol 1976; 41: 101-106.

6. Peslin R. Lung mechanics II: resistance measurements. Bull Eur Physiopathol Respir 1983; 19: Suppl. 5, 33-38.

7. Nagels $\mathbf{J}$, Landsèr FJ, Van der Linden L, Clément $\mathbf{J}$, Van de Woestijne KP. Mechanical properties of lungs and chest wall during spontaneous breathing. $J$ Appl Physiol 1980; 49: 408-416.

8. Solymar L, Landsèr FJ, Duiverman E. Measurement of resistance with the forced oscillation technique. Eur Respir J 1989; 2: Suppl. 4, 150s-153s.

9. Demedts M, Van Noord J, Van de Woestijne KP. Clinical applications of the forced oscillation technique. Chest 1991; 99: 795-797.

10. Van Noord JA. Oscillation mechanics of the respiratory system: clinical applications and modelling. $\mathrm{PhD}$ thesis, University of Leuven, Leuven, 1990.

11. Zwart A, Peslin R. Mechanical respiratory impedance: the forced oscillation method. Eur Respir Rev 1991; 1: 131-237.

12. Zwart A, Van de Woestijne KP. Mechanical respiratory impedance by forced oscillation. Eur Respir Rev 1994; 4: 114-237.

13. Brusasco V, Schiavi E, Basano L, Ottonello P. Comparative evaluation of devices used for measurement of respiratory impedance in different centres. Eur Respir Rev 1994; 4: 118-120.

14. Van de Woestijne KP, Desager KN, Duiverman EJ, Marchal F. Recommendations for measurement of respiratory input impedance by means of the forced oscillation method. Eur Respir Rev 1994; 4: 235-237.

15. Mead J. Contribution of compliance of airway to frequency dependent behavior of lungs. J Appl Physiol 1969; 26: 670-673.

16. Cauberghs M, Van de Woestijne KP. Effect of upper airway shunt and series properties on respiratory impedance measurements. J Appl Physiol 1989; 66: 2274-2279.

17. Hellinckx J, De Boeck K, Demedts M. Evaluation of impulse oscillation system: comparison with forced oscillation technique and body plethysmography. $\mathrm{Am}$ J Respir Crit Care Med 1997; 155: A865.

18. Franken $\mathbf{H}$, Clément $\mathbf{J}$, Cauberghs $\mathbf{M}$, Van de Woestijne KP. Oscillatory flow of a viscous compressible fluid through a rigid tube: a theoretical model. IEEE Trans Biomed Eng 1981; 23: 416-420.

19. Dubois AB, Botelho SY, Comroe JH. A new method for measuring airway resistance in man using a body plethysmograph: values in normal subjects and in patients with respiratory disease. J Clin Invest 1954; 35: 327-335.

20. Bland JM, Altman DG. Statistical methods for assessing agreement between two methods of clinical measurement. Lancet 1986; i: 307-310. 